\title{
REPORT OF COMMITTEE
}

\section{DRAFT OF PROPOSAL FOR THE SUPPORT OF ASTRONOMY BY THE NATIONAL SCIENCE FOUNDATION}

The American Astronomical Society authorized a special committee to study relations between astronomers and the National Science Foundation. This committee, with the support and approval of the Council of the American Astronomical Society, makes the following recommendations.

I. Administration. In 1948 a Committee on Astronomy, Advisory to the Office of Naval Research, was established by the National Research Council. Appointments to this committee are based upon recommendations from the Council of the American Astronomical Society. Members are appointed to the committee for a fixed term of three years and cannot be immediately reappointed; representatives of both large and small observatories and institutions are included on the committee. The success that this committee has had in appraising applications for financial support of research projects in Astronomy and in advising ONR regarding the administration of contracts resulting therefrom, leads to the suggestion that the same committee could also serve in an advisory capacity to the administration of the Foundation. It could evaluate the scientific merit of requests for funds in the field of astronomy and transmit its recommendations to the National Science Foundation. Accordingly it is recommended that the present committee of seven professional astronomers which has served in an advisory capacity to the Office of Naval Research, be continued as an advisory body on astronomical matters to the National Science Foundation.

II. Budget. The fundamental policy recommended by the committee is that in the first years only a cautious beginning should be made; policies must be adjusted slowly to obtain maximum utilization of manpower and funds. The proposed budget estimate for the first year of full operation of the Foundation is, in outline, respectfully submitted. Each item in the budget was discussed in detail by the council of the A.A.S. Rather than make a request for a sum for which efficient use might not be immediately attained, we have proposed essentially a minimal budget.
Proposed Budget in Astronomy

July I, I95 I to June 30,1952

A. Fellowships

$\$ 35,000$

35,000

B. Publications

160,000

C. Short-term Research Projects

D. Capital Equipment Grants

I 50,000

$\$ 380,000$

Individual items are reviewed below.

$A$. The prime requisite for successful expansion of the field of astronomy is the support of brilliant young men interested in pure science who now must enter fields of industry, engineering, and physics where the ultimate salaries are high and financial security greater. Universities and observatories can now offer mainly teaching fellowships and assistantships of small amounts. It is necessary to provide twelve to fifteen additional graduate fellowships per annum to meet the required support of students working toward the Ph.D. degree. The average rate of graduation of Ph.D. students has been about eight per year and is momentarily higher. Good men, however, are in very great demand, and major positions are open in several observatories for lack of suitable candidates.

$B$. The cost of publication of scientific papers has increased between two and threefold. The major astronomical journals of this country are run at a loss, and have no permanent endowment. They are thus supported by page charge payments by observatories and individual authors and by the A.A.S. A large over-crowding of the journals exists and publication is subject to long delay. Astronomical monographs are difficult to publish at all, and major completed research monographs already exist which will require approximately $\$ 15,000$ to publish which is not otherwise available. An additional $\$ 10,000$ is needed to permit expansion of the number of pages of the journals and a reduction of charge per page to the observatories to help meet the costs of the increased volume of completed researches and the high present page charges.

$C$. The experience of the committee advisory to the ONR has been that with an upper limit of $\$ 5,000$ per project a total amount of $\$ 160,000$ was applied for in $195 \mathrm{I}-52$. Funds were insuffi- 
cient and thus projects aggregating $\$ 80,000$ could not be undertaken; about 30 grants were made. The work of approximately 75 astronomers and assistants is being very effectively aided by this program. The experience, now in the fourth year, has been that these small grants to support short-term research programs have been of great value to science. It is proposed that a larger upper limit near $\$ 10,000$ per project be set; based on experience with the ONR, a first year's allocation of $\$ 160,000$ is required to accommodate a few larger grants and the expected number of small ones. This would provide assistance and minor equipment in specific programs. Besides the support of research at existing large observatories special weight has been and probably should continue to be given to projects which encourage research at smaller institutions, with a wide geographical distribution.

$D$. During the 25 years from 1923 to 1948 , which includes the depression and the war, telescopes and auxiliary equipment were built at a total cost of about $\$ 2,000,000$ (excluding the 200 -inch). In view of the increase in cost of precision equipment, it must be estimated that the replacement cost would be near $\$ 5,000,000$; the annual rate of $\$ 200,000$ is thus indicated for future years unless the rate of progress in astronomy is to be reduced in the future. Older equipment also will tend towards obsolescence without such expansion. In this figure we have not included the cost of the Palomar Observatory $(\$ 6,500,000)$, or of eclipse expeditions and special equipment; inclusion of these items would bring the past total expenditures for equipment, without allowance for increased construction costs, to about $\$ 400$,ooo per annum over the last 25 years. There are about 40 institutions at which astronomical research is being carried on.
In the first year of operation it is not proposed that large new facilities be provided. The major and very immediate need is to provide funds for several large grants for the modernization of existing telescopes and the construction of auxiliary equipment used in the analysis of the observation. In several major observatories large telescopes are approaching the point of obsolescence because of the high cost of modern electronic drive and control equipment and precision mountings. The expansion of the cities near which universities were built has in many cases rendered present locations unsuitable for research. Modernization of existing equipment and construction of devices for measurement and analysis of data will permit an effective expansion of research to be obtained with minimum of cost and delay.

Care should be exercised in the administration of funds so that universities would continue to carry their proper share in the support of astronomical research and should not use the proposed grants from the National Science Foundation to escape the expenditures for astronomy that they would otherwise make.

Large increases in the rate of astronomical research will require much greater funds than are proposed here, and in the first year no provision is made for beginning any such expansion. Such an expanded program can be achieved over a period of many years, as the number of trained astronomers gradually increases. Our present estimate of requirements in longer-term grants for urgently needed expansion of capital equipment is an additional $\$ 200,000$ per annum. This is omitted from the present budget because of the immediate need for training and rehabilitation.

\section{NEW BOOKS RECEIVED}

Astrophysics. A Topical Symposium. Edited by J. A. Hynek. (xii +703 pp.) McGraw-Hill, I95I. \$12.00

Katalog der südlichen Bonner Durchmusterung. (Deklinations-Zonen $-2^{\circ}$ bis $-22^{\circ}$ ) revised edition in a micro-volume, obtainable from Ferd. Dümmlers Verlag, Bonn. Price DM 42. The Atlas for these zones was noted in this column in A.J. 56, II2. Catalogue and Atlas of the northern zones are in preparation. 